Kindie Birhan Fenta

Department of Curriculum Studies

College of Social Sciences and Humanities

Injibara University

Ethiopia
Original scientific paper

UDK: 378.096 .147

DOI: $10.17810 / 2015.95$

\title{
INSTRUCTORS' CONTRIBUTION TO PROSPECTIVE TEACHERS' EXPERIENTIAL LEARNING IN PRESERVICE SECONDARY SCHOOL TEACHER EDUCATION PROGRAMME
}

\begin{abstract}
Ethiopian public universities are expected to employ experiential approaches to learning in pre-service secondary school teacher education. Accordingly, this study was carried out in three public universities to investigate participants' perception toward instructors' role in facilitating trainees' experiential learning. Parallel mixed methods design was employed in the research. Quantitative data were collected from 311 trainees using questionnaire. On the other hand, qualitative data were gathered from 9 instructors and 30 trainees employing interview and focus group discussion respectively. The t-test results uncovered that the instructor's support to the trainees' experiential learning was significantly less than the expected one. The t-test results also disclosed lack of significant difference in the instructors' support to the trainees' experiential learning across gender and teaching experience. Likewise, the one way ANOVA results uncovered the absence of significant difference in the instructors' support to the trainees' experiential learning across CGPA. The instructors' limitation in flexibly reorganizing the trainees' seating arrangement, utilizing learning activities that facilitate experiential learning, initiating and facilitating the trainees' classroom interaction and discussion, and providing the trainees with timely feedback and support in the instruction hampered the trainees' experiential learning. Thus, the instructors are required to take measures that improve these obstructive practices.
\end{abstract}

Key words: teacher education, experiential learning, instructor's instructional role.

\section{INTRODUCTION}

Teacher education is a backbone of the success of any education system (Tabot and Mottanya, 2012). The extent to which it prepares quality teachers determines the degree to which the education system of a country attains its objectives (MacKinnon and Scarff-Seatter, 1997). In line with this, scholars in the field of education claimed that as a teacher is the most important factor in determining student learning and achievement (Borko, 2004; Darling-Hammond, 2000), the teacher education programmes need to assure the quality and commitment of its teachers (Oliveria and Farell cited in Ayalew, 2009). Likewise, Harris and Sass (2008) and

\footnotetext{
${ }^{1}$ kindaybir@gmail.com
} 
Mpokosa and Ndaruhutse (2008) stated that the teacher education programmes need to prepare well-qualified teachers who contribute to the development of a nation.

The preparation of competent professional teachers can be realized by enabling prospective teachers to play active role in the instruction. Because, genuine learning is active but not passive and people of all ages learn best when they involve in a meaningful learning experience (Wortman, 1988). Related to this, Bonwell (1996) and Fink (2003) added that, in the realm of education, learners who involve actively in learning activities become more interested in the learning material, comprehend better, and retain longer. By the same token, Behr and Temmen (2012) stated that content learned in an experiential context through selfdiscovery and practical application is retained for far longer and can be accessed and transferred far more readily than content learned through traditional lecture.

This is for the reason that, throughout the experiential learning process, the learner is expected to be challenged to take initiative, make decisions, pose questions, investigate, solving problems, assume responsibility and construct meaning (Boud, Cohen and Walker, 1993). In other words, experiential learning that can be enacted by asking participants to share stories, use case studies, do problem solving exercises and use any activity that gets students involved in small group discussions, experiments, role plays, building something at their table or desk, and writing or drawing something specific significantly increases a learner's retention rate (Rasmussen, 2015).

As these descriptions indicate that experiential learning is grounded in the theoretical framework of personal experience (Ausburn and Brown, 2006), the students need to have experiential learning opportunities that facilitate their active participation in the instruction (Bartle, 2015). That is, the students need to get learning opportunities that encourage their experience, reflection, dialogue, critical thinking, knowledge ownership, understanding in context, and application (Bartle, 2015; Black and Ammon, 1992; O' Loughlin, 1992; Zichner and Gore, 1990). The adequate enforcement of the experiential learning experiences in the instruction can be facilitated by providing the students with adequate and timely support and feedback (Kolb \& Kolb, 2005).

Particularly, in formal educational contexts, experiential learning is concerned with educational activity exploited (Moon, 2004; Robert, et al., 2010). That is, in this context, experiential learning is related to learning undertaken by students who are given a chance to obtain and apply knowledge, skills and feelings in an immediate and relevant setting (Smith, 2001). In other words, the term experiential learning is used by educators to describe a series of pragmatic activities sequenced in such a way that it enhances the educational experience for the learner (Robert, et al., 2010). This the direct experiential encounter with a learning event (Borzak, 1981) requires active engagement of the student as opposed to passive engagement commonly associated with teacher directed instruction that involves minimal student interaction in the learning process (Robert, et al., 2010). Here, the students - as main participants in the learning process -need to be actively involved, encouraged to present questions, to investigate, to experiment, to show their curiosity, to get involved in solving problems, to assume responsibilities, to be creative, to have initiative, to make decisions and to be responsible for the results. That is, the students need to involve in the instruction intellectually, emotionally, socially and/or physically (Gorghiua and Santib, 2016). 
As reflection is a key component to learn from experience and make an experience worthwhile (Dewey, 1938), the students are required to continually self-evaluate their progression in the learning process through constant reflection (Fry, et al., 2009). This indicates that experiential learning requires students to reflect on their novel experience (Moon, 2004). As an integral component to the learning process, the reflection made on learning experience leads to analysis, critical thinking and synthesis (Boud, Cohen \& Walker, 1993). Here, it is vital to notice that if the reflection component is omitted, the students are not engaging in theory-based experiential learning and are being denied the opportunity for greater learning through experience (Robert, et al., 2010). In other words, when learning stops at the experience it limits the learner's capacity to reflect on the experience and to acquire a deeper understanding from it (Robert, et al., 2010). Due to this reason, the students are required to critically reflect on their experience, both while it is happening and subsequently and consciously create meaning and conceptualization from the experience (Gamble, Davey \& Chan, 1999).

Here it is vital to take in that experiential learning boasts as one of the foremost sciences (Bransford, Brown, \& Cocking, 2000) that encourage students to learn through a process rather than to place the majority of emphasis on outcomes (Dewey, 1897). That is, it positions learning as a continuous process in which students bring their own knowledge, ideas, beliefs and practices to their understanding and interpretation of new information. In turn, this transformative process shapes the changes in their understanding and interpretation of theory, beliefs, values and practice (Ambrose, et al., 2010; Cooper, et al., 2010).

The experiential learning aligns with constructivism which posits that learners construct meaning from their experiences (Doolittle and Camp, 1999 cited in Robert, et al., 2010). Accordingly, the constructivist view of experiential learning claims learners to be active constructors of knowledge, skills and attitude through their active engagement in the learning experience (Dewey, 1938; Kolb, 1984; and Wells, 1995).

The constructive view of experiential learning supports the reform models for education that alter the role of the instructor from actually delivering knowledge to being a facilitator of knowledge construction (Knoblauch, 2003). That is, the reform models shift the learning design from being teacher-centered where teaching is largely transmission of teacher's knowledge in the learning material to an approach that requires students to cooperate and learn from one another through direct experiences (Kolb \& Kolb 2009). This is informative that the instructor's role in experiential learning is oriented on guiding or facilitating the students' involvement in the knowledge construction process rather than concerned with imposing on the learner the instructor's own knowledge in the learning material (Kolb \& Kolb 2009). That is, in experiential learning, the instructor is the facilitator of learning by planning and organizing suitable learning opportunities for their students and providing meaningful resources to help their students succeed. In essence, the instructors guide rather than direct the learning process. They also ensure physical and emotional safety and support learners throughout the process. In doing this, the instructors need to carefully choose adequate experiences that facilitate the students' observation, heuristic conversation, brainstorming, case study, role play, educational games, simulation, presentation, group-work methods etc. They also need to play a role of counselling, offering adequate resources to students, creating conditions of physical and emotional safety and facilitating the learning process by providing feedback and support. Moreover, they must encourage the students' initiatives, and get students involved in the challenging learning experiences (Gorghiua and Santib, 2016). 
In Ethiopia, the absence of mode of presentation of the learning material that can develop student's cognitive abilities and behavioral change and can adequately enrich their problemsolving ability and attitude contributed to the low quality of teacher education. Specifically, before implementing the post graduate diploma in teaching (PGDT) programme, the teacher education was characterized by theoretical and teacher-centered quality of courses and methods of teaching (MOE, 2003). In addition to this, the insufficient training of teachers made the teaching competence and professional ethics of teachers to be below the expected standard (TGE, 1994).

Cognizant of this, a synchronized effort was made to improve the quality of education in general (MOE, 2009). For instance, policy measures were taken by the government of Ethiopia to improve the quality of education in general and teacher education in particular. Particularly, the education and training policy that has given emphasis to the development of a student's problem solving capacity has given emphasis to provide the trainees with practical trainings in the teacher education (TGE, 1994). Moreover, in the attempt to enforce the new education and training police of Ethiopia (TGE, 1994) a task force was formed to further study additional specific problems facing the teacher education sector and forward possible solution thereby to improve the quality of the education system of the country (Ahmed, 2013). Then, the task force investigated that Ethiopian teacher education had multifaceted problems and needed a major overhaul (MOE, 2003). It investigated that the professional competence of teachers was deficient; the teaching skills and techniques were very basic; teachers did not match up to the standards and expectations of their profession; the quality of courses and methods of teaching were theoretical and teacher centered; and professionalism and ethical values were not maintained. As a result, the national teacher education programme reform known as Teacher Education System Overhaul (TESO) was initiated by the ministry of education in 2002 (MOE, 2003).

Then, teacher Education System Overhaul (TESO) produced a framework detailing a paradigm shift in the pre-service teacher education programme. This paradigm shift required the presence of learning opportunities characterizing a constructivist paradigm (MOE, 2003; Mulugeta, 2009). That is, the teacher education was required to make a paradigm shift from teacher-centered to student- centered instruction that advocates constructivism (Adula \& Kassahun, 2010; MoE, 2009; Mulugeta, 2009; Reda, 2015). It involves teaching which makes change in taking the real world in to the classroom and taking trainees out into the real world. Besides, democratizing teacher education and giving confidence to students to make decisions, to take initiatives and to take control of their own learning were considered. It does mean that the teacher education programme needed learning opportunities that characterize a constructivist paradigm (MOE, 2003; Mulugeta, 2009). In addition to this, the TESO planted very well in the programme about the relevance of active learning and continuous assessment (MOE, 2003; MOE, 2009). In this regard, the instructors were required to present lessons in engaging and motivating manner by utilizing learning experiences that facilitate the trainees' experience, reflection, conceptualization, and application (MOE, 2009). Thus, it is vital to notice that this paradigm shift supported the constructivist view of experiential learning that claims a learner to construct one's own knowledge in a learning material (Dewey, 1938; Kolb, 1984; and Wells, 1995). However, the studies made after the implementation of the TESO programme indicated that the teacher education was entangled with problems that were very much similar to the ones that initiated the TESO reform. That is, the professional competence of teachers was deficient; the teaching skills and techniques were very basic; teachers did not match up to the standards and expectations of their professions; the quality of courses and 
methods of teaching were theoretical and teacher centered; active learning methods were not properly and sufficiently employed; professional commitment and work ethics were not demonstrated as desired; and teachers' interest to follow up and assist students was low. In general, much of the input and process factors of teacher education remained unchanged (MOE, 2003). These seemed to indicate that the student teachers had limited experiential learning practice while implementing the TESO programme.

Due to this reason, it was believed that reforming the secondary teacher education programme was in order. To this end, a national task force was set up to investigate the problems and forward the solution to the problems that faced the teacher education programme. The task force came up with experiences that the secondary school pre-service teacher education was delivered in many countries mainly in a postgraduate certificate form. Accordingly, the government of Ethiopia set up the Post Graduate Diploma in Teaching (PGDT) programme which came in to effect in 2009 with the intention to build a teacher education programme that emphasizes on pragmatism and reflective practitioner orientations (MOE, 2009).

One of the missions of the PGDT programme has been promoting reflective and social pragmatic principles and practices of teaching and learning (MOE, 2009). With this mission, the programme has been intended to enable trainees to become reflective practitioners who are able to analyze, evaluate and act to improve their own practice and develop further professional knowledge and skills. The programme has also intended to provide teacher trainees with the theoretical and practical experience they need to achieve all the standards and competencies set by the Ministry of Education such as facilitating student teachers' learning; assessing student teachers' learning; and using the information for improving teaching practices and student teachers' learning (MOE, 2009). In other words, the programme has been set to facilitate student teachers' experiential learning through practicing/applying diverse active and reflective instructional techniques; using subjectspecific pedagogical knowledge and academic knowledge to provide learning experiences that are related to experiential learning; and presenting lessons in engaging and motivating manner (MOE, 2009, Mulugeta, 2009).

In addition to this, the PGDT programme has been set up to facilitate learning by monitoring and assessing student teachers' learning progress continuously. This enables instructors to provide timely and constructive feedback to student teachers and use it as the basis for ongoing planning of teaching. Related to this, the process of the secondary teacher education preparation that has advocated the principles of reflective practice and team approach of learning has been desired to involve value orientations of learner-centeredness and pragmatism (MOE, 2009, Mulugeta, 2009). Here, enabling teacher trainees to become reflective practitioners, to improve their own practice and to develop further professional knowledge and skills has been the focal point of the programme. All these indicate that experiential learning has got emphasis in the PGDT programme.

In other words, teacher educators have been required to facilitate student learning rather than to transmit course related information to the trainees. They have been expected to actively manage instructional environment and learners' behavior in the teaching learning process (MOE, 2009). This gives teacher trainees opportunity to experience, reflect, conceptualize, and apply diverse active and reflective instructional techniques and promote their construction of knowledge in the courses offered. As learner-centeredness and 
pragmatism are the guiding values of the process of secondary school teacher preparation in the programme, teacher educators need to constantly construct powerful learning experiences that facilitate experiential learning of the trainees (Kolb, 1984; and Wells, 1995). Because, provision of the trainees with learning opportunities that encourage reflection, dialogue, critical thinking, knowledge ownership, and understanding in context and within learning communities facilitates their experiential learning practice (O' Loughlin, 1992; Zichner and Gore, 1990).

That is, the trainees can be stimulated to transform the conceptual content of lectures, readings, and their classmates' reports with the purpose of discovering their opinions, beliefs, values, principles, and applied approaches for controversial education issues (Tatto, 1998). This can be done by carefully assessing the trainees' progress and understanding; thoughtfully supporting learner's academic and emotional progress, understanding, and practice; and helping them to link theory and practice. These practices can help the trainees to have a command of critical ideas and skills; the capacity to reflect on, and learn from their practice oriented course related learning experience. Related to this, the application of teacher education pedagogies such as micro-teaching, analysis of teaching and learning, case methods, and problem solving are some important learning strategies that can be employed in the programme. Thus, the trainees need to work in small, stable groups, closely followed by the instructors (Dewey, 1938; Kolb, 1984; and Wells, 1995).

Although the instructors have been expected to play roles that support the trainees' experiential learning in the PGDT programme, they might have executed these roles as expected or otherwise. Thus, it was reasonable to assess the extent to which the instructor's executed expected instructional roles that facilitate the trainees' experiential learning. In addition to this, it was likely to investigate the factors that affected the instructors' instructional role in this teacher education programme. On top of this reason, the study was carried out in 2016/17 academic year in three public universities with the intention to:

- investigate the extent to which the instructors supported the trainees' experiential learning

- identify the factors affecting the instructors' contribution to the trainees' experiential learning.

To attain the abovementioned objectives of the study, the following research questions were specified:

- What is the extent to which the instructors supported the trainees' experiential learning?

- What are the factors affecting the instructors' contribution to the trainees' experiential learning?

The results of the study enable stakeholders of the PGDT programme such as instructors, trainees, PGDT programme coordinators, college deans, university officials and ministry of education to understand the extent to which the instructors contributed to the trainees' experiential learning in the programme. Moreover, they enable these stakeholders to comprehend the factors that either impede or support the instructors' contribution to the trainees' experiential learning in the programme. Furthermore, the paper adds to emerging literature in authorizing the trainees' and instructors' voice in teacher education geared toward the instructors' contribution to the trainees' experiential learning. 
However, the study was not without any limitation. That is, for the trainees were busy enough taking intensive on- campus courses and practicum out of campus in a short period of one academic year, the researcher encountered shortage of time required to gather more in depth qualitative data.

\section{Materials and Methods}

A convergent parallel mixed methods research design was employed in the study. Subjects of the study included the winter modality pre-service secondary teacher education trainees and instructors selected in each of the study universities. The target universities included Bahir Dar University where the researcher was pursing Ph.D and Wollega University and Debre Markos University that are found in a near distance to Bahir Dar University. The universities were purposively selected to collect data with low travel and other costs. The quantitative data were collected from 311 trainees using questionnaire. The stratified simple random sampling techniques were employed to proportionally select the trainees from different departments. Instead, the qualitative data were collected in each of the study universities from purposively selected 3 instructors and 10 trainees. The purposive sampling technique was employed to select instructors thought to voluntarily provide adequate and relevant interview data. In addition to this, with the researcher's belief that the classroom representative trainees give better data, these trainees were purposively selected to participate in the focus group discussion. Then, the data were collected using the interview and focus group discussion guide questions developed by the researcher from the reviewed related literature.

The questionnaire which contained 10 statements with five point Likert type scale was developed by the researcher from the reviewed related literature. The favorably stated questionnaire statements were scored as Strongly Agree (5), Agree (4), Undecided (3), Disagree (2), and Strongly Disagree (1). Here, higher score means that the instructor had higher positive contribution to the trainee's experiential learning. Whereas lower score means that the instructor had lesser positive contribution to the trainee's experiential learning.

Before employing the questionnaire for data collection in the main study, the pilot taste of the questionnaire was made to check the reliability of the instrument. However, before conducting the pilot study of the questionnaire, the content validity of the scale was judged by three teacher educators selected at Bahir Dar University. That is, the three teacher educators evaluated the appropriateness of the items of the questionnaire to represent what they were assumed to represent in the study. This was done for the reason that this technique enables the researcher to secure content validity (the degree to which an instrument is representative of the topic and process being investigated) (Colton and Covert, 2007). While conducting the pilot study of the instrument, the values of unfavorable statements were reversed for data analysis. The result indicated that the Cronbach alpha $(\alpha)$ reliability coefficient of the questionnaire was 0.753 .

Having conducted the pilot study of the instrument, the researcher utilized the instrument to collect data in the main study. However, before collecting data for the main study, course instructors were introduced about the purpose of the study and requested to allow their instructional time to collect data from the trainees. Likewise, the respondents of the questionnaire were introduced about the purpose of the study, the confidentiality of the data and the procedure of filling the data. Then, having obtained the consent of the respondents to fill the questionnaire and instructors to allow their instructional time for data collection, the 
researcher himself collected the quantitative data from the trainees in their respective classrooms.

On the other hand, the semi-structured interview and focus group discussion guide questions were developed by the researcher from the reviewed related literature and employed to collect the qualitative data. With the consent of the trainees and course instructors, focus group discussion and interview were made in each of the study universities. Both data were collected from the respondents in the presence of the researcher. Here, the researcher served as a facilitator and data collector.

The collected quantitative and qualitative data were analyzed separately. The quantitative data were analyzed using descriptive statistics (frequency, percentage, mean and standard deviation) and inferential statistics (t-test and ANOVA). On the other hand, the qualitative data were analyzed employing thematic analysis technique. Having done this, interpretation of the findings of the quantitative and qualitative data analyses was made concurrently. Following this, summary, conclusion and implication of the findings were made respectively.

\section{Results and Discussion}

\section{Data Analysis Procedure}

The quantitative data were scored and analyzed using frequency, percentage, mean, standard deviation, one sample t-test, independent samples t-test and one way ANOVA. The frequency, percentage, mean and standard deviation were employed to describe the perceptions of the trainees toward the contribution of the instructors to their experiential learning. A one sample t-test was employed to compare rated mean value of the trainees with expected mean value. Independent sample t-test was computed to uncover the observation of the trainees toward the contribution of instructors to their experiential learning as a function of gender and teaching experience. On the other hand, one way ANOVA was computed to examine the trainees' observation toward the instructors' contribution to their experiential learning as a function of CGPA. Moreover, the qualitative data were analyzed employing the thematic analysis technique to assess the factors that affected the instructors' contribution to the trainees' experiential learning.

\section{Data Presentation and Analysis}

The quantitative data analysis was made based on data obtained from 311 trainees. Instead, the analysis of the qualitative data was made based on the FGD and interview data collected from 30 trainees and 9 instructors respectively selected in all of the study universities.

Table 1: Descriptive Statistics of the Trainees' Perception Scores on the Instructors' Contribution to the Trainees' Experiential Learning $(\mathrm{N}=311)$

\begin{tabular}{|l|l|l|l|l|l|}
\hline Perception towards & $\mathrm{N}$ & Mean & SD & Minimum & Maximum \\
\hline $\begin{array}{l}\text { Instructor's Contribution to Experiential } \\
\text { Learning }\end{array}$ & 311 & 26.56 & 4.79 & 16.00 & 38.00 \\
\hline
\end{tabular}


As table 1 depicts, 311 subjects' mean score on their perception toward the instructors' contribution to the trainees' involvement in experiential learning in the PGDT programme was $26.56 \pm 4.79$ out of 50 (53.12\%). The instructors' $53.12 \%$ contribution to the trainees' experiential learning practice was less than that of their $60 \%$ expected average contribution. The same table also depicts that the trainees' minimum and maximum perception scores were 16.00 and 38.00 out of 50 respectively. The existence of minimum scores highly moved below the median score (26.00) informed that there were instructors with low contribution to the trainees' experiential learning.

Table 2. Results of t-test for Comparison of Trainees' Rating Score on Instructors' Contribution to the Trainees' Experiential Learning with that of Expected Mean Score $(\mathrm{N}=311)$

\begin{tabular}{|l|l|l|l|l|l|l|l|}
\hline Perception Towards & $\mathrm{N}$ & $\begin{array}{l}\text { Rated } \\
\text { Mean }\end{array}$ & $\begin{array}{l}\text { Expected } \\
\text { Mean }\end{array}$ & SD & Df & T & Sig. \\
\hline $\begin{array}{l}\text { Instructor's contribution to the } \\
\text { Trainee's Experiential Learning }\end{array}$ & 311 & 26.56 & 30.00 & 4.79 & 310 & $-12.682 *$ & .000 \\
\hline
\end{tabular}

* $\mathrm{P}<0.05$

As table 2 shows, at 0.01 alpha level, $t(310)=-12.682, P<0.01$, there was statistically significant mean difference in the trainees' observation toward the instructors' contribution to their experiential learning. That is, the trainees' rated mean score (26.56) on the instructors' contribution to their experiential learning was significantly less than that of their expected mean score (30.00).

Similarly, the qualitative data analysis findings presented below under the specified themes supported the quantitative data analysis findings.

\section{Classroom Seating Arrangement}

The majority of the focus group discussants affirmed that the instructors most of the time encouraged the trainees' seating arrangement to be rigidly organized in rows face to face to the blackboard. That is, they did not encourage them to flexibly reorganize their seating arrangement overtime in such a way that facilitates their active involvement in the instruction. Even though some instructors sometimes asked the trainees to reorganize their seating arrangement to involve especially in group learning activities, the low interest the trainees had in the programme discouraged them to do so. Likewise, lately commencing of course delivery that resulted in shortage of instructional time and the crowded classrooms found in the study universities did not allow instructors to flexibly reorganize the trainees' seating arrangement in such a way that facilitates their active involvement in the instruction. In addition to this, particularly in BDU, as all the discussants who learned in New Class Rooms (NCR) informed, the NCRs were equipped with chairs regularly arranged only on one side of long and wide rectangular tables. Consequently, the instructors frequently lectured more content within a short period of time using the blackboard as well as the PowerPoint presentation. Like what the focus group discussants mentioned, almost all the interviewed instructors witnessed that they had limitations in flexibly reorganizing the classroom seating arrangements in such a way that facilitates the trainees' involvement in the instruction. That is, they frequently encouraged the trainees to sit in rows arranged face to face to them and attend their lecture made on course contents. 
As most of the instructors said, the trainees' low interest to actively attend the courses, lately commencing of course delivery that resulted in shortage of instructional time and the intention of instructors to finish course delivery within a short period of instructional time resulted in the trainees' frequent and rigid face to face seating arrangement. Related to this, in BDU, more of the interviewees who taught in the classrooms crowded with armchairs in FBE did not want to waste time to remove unwanted armchairs and reorganize the trainees' seating arrangement in the way that facilitates their involvement in different active learning activities. Similarly, due to the existence of big and long rectangular tables in NCR in BDU, the instructors could not enforce the flexible reorganization of seating arrangement over time. Moreover, since the classrooms were crowded with armchairs in WU and DMU, the instructors frequently lectured to the trainees seating in rows regularly arranged face to face to the instructor. Of course, there were few instructors who infrequently advised the trainees to flexibly reorganize their seating arrangement for cooperative learning. However, the trainees mostly preferred to sit permanently looking face to face to the instructor. On top of this, the instructors frequently lectured to the trainees. This was likely to facilitate the trainees' rote learning.

\section{Learning Activity}

The majority of the focus group discussants indicated that the instructors frequently lectured on the course content than provided the trainees with learning activities that facilitate their involvement in the knowledge construction process. In other words, the learning activities provided to the trainees were most of the time limited to listening to the instructors' lecture and taking notes. For instance, in BDU, the majority of the discussants had similar observation to what one of the discussants said that most of the instructors frequently made lectures that helped him to absorb information for the purpose of passing tests and exams. Of course, few instructors infrequently provided them with learning activities that involved them in learning tasks done individually, in pairs and in small groups. This implies that the trainees most of the time learned by listening to what most of the instructors talked about the course content rather than learned by involving in different learning activities by themselves.

As more of the discussants observed, this was due to the fact that the instructors who lately commenced course delivery preferred to make lectures on bulky course content within a short period of instructional time than to involve the trainees in the instruction. In addition to this, the trainees who had low interest to the teaching profession also preferred to attend lectures, to read the hand out and sit for exam than to involve in learning activities. Moreover, the trainees who entered in to conflict with the university administration body that did not provide them with food, dormitory, and pocket money payment services on time were discouraged to involve in the instruction.

Like what the trainees observed, almost all the interviewees assured that although they infrequently provided learning activities that directly involve the trainees in pair and group learning activities, they most frequently limited the learning activities given to the trainees to listening lectures and taking pieces of information from these lectures. That is, the instructors failed to frequently provide the trainees with learning activities that adequately facilitate their active involvement in the instruction. Related to this, for instance, one of the interviewees indicated that although giving lecture was not his primary preference, as the trainees had no interest to participate in the instruction, he frequently lectured on the course content to the trainees. The other interviewees also added that the shortage of instructional time 
encountered them to cover the course content, the crowded classroom space and the trainees' preference to read the handout outside of the classroom for exam forced them to make frequent lecture.

\section{Classroom Interaction and Discussion}

The majority of the focus group discussants in the study universities disclosed that, although the instructors are the main agent to initiate and facilitate the trainees' classroom interaction and discussion, they could not frequently execute it. That is, with the intention to cover large course content within a short period of time, most of the instructors were frequently transmitting pieces of course related information through their lectures rather than initiating and facilitating the trainees' classroom interaction and discussion. For instance, the majority of them agreed with what one of the discussants put that only few instructors infrequently involved the trainees in pair and small group discussions. Likewise, more of the discussants supported what the other trainee expressed that he most of the time individually absorbed what his instructors told about the course content. In other words, although some instructors infrequently initiated and facilitated the trainees' classroom interaction and discuss, most of them facilitated individual learning than cooperative learning.

According to most of the discussants, these practices resulted from the instructors' lately starting of course offering. This in turn resulted in frequently made lectures executed to cover bulky course content within a remaining short period of instructional time. In addition to this, classrooms crowded with armchairs and low interest of the trainees to the program hampered the trainees' cooperative learning.

Like what the FGD participants of the study universities said, the interviewees participated in the study universities disclosed that they could not frequently initiate and facilitate the trainees' classroom interaction and discussion. That meant that, through their frequently made lectures, the instructors facilitated individual learning than cooperative learning. Of course, few instructors tried to provoke the instructors' thought process through questions posed to individual trainees. But, the trainees did not get frequent chance to interact and discuss among themselves in pair and small learning groups. Moreover, although some instructors infrequently gave some questions and assignments to the trainees to discuss in groups, the trainees did not show willingness to actively participate in such kind of learning activities. Even sometimes, when each group member was asked to present what was discussed in the group learning activities, he/she was not willing to do so. Rather, the group members usually left the presentation to be done by the same person or persons in a group. These practices encouraged the instructors to frequently give lecture to the trainees.

Here, most of the instructors told that the shortage of instructional time that encountered them to cover the bulky course content, the crowded classroom space, and the trainees' low interest to learn cooperatively forced them to make frequent lecture in the classroom.

\section{Feedback and Support}

The majority of the FGD participants witnessed that they did not receive frequent and adequate academic feedback as well as emotional support from their instructors in the classroom. For instance, more of the discussants accepted what one of them presented that except the subject matter teacher who provided feedback on what he sometimes presented 
in the classroom, other course instructors did not frequently provide him with timely feedback and support on the learning tasks and assessment results. The instructors were most of the time simply running to cover the course content through their frequently made lectures. That is, since the discussants were most frequently listening to lectures and taking notes, they were not in a position to receive feedback and support from the instructors. Of course, one of the discussants disclosed that only one of his instructors used to inform the trainees how to solve emotional problems in the classroom. However, most of the trainees who were upset with the maladministration of the university administration in providing them with timely services of food, dormitory and pocket money payment never noticed the time they received emotional support from the instructors.

Of course, most of the discussants described that only few instructors sometimes provided feedback to the individual or group learning tasks done and presented to the class. That meant that the feedback given was most of the time limited to the assignments done and presented in the classroom than to other involving classroom learning activities. Although few instructors infrequently gave immediate feedback on test and exam results and group assignment works presented to the class, the feedbacks were most of the time limited to show mistakenly or correctly done assessment tasks but not used to involve them in learning activities. That is, having taken tests and exams, the trainees did not most of the time receive immediate feedback on test and exam results. Rather, they frequently used to see only the final assessment letter grades. This consolidates what one of the discussants told that in the second semester the assessment and evaluation course instructor could show test, quiz, and exam results once before summing up them. Even when the trainees submitted written assignment, the instructors did not often give feedback on what they did. Rather, they told to the trainees only the assessment value they scored, mostly at the end of the course delivery.

Likewise, most of the interviewees noticed that they did not provide the trainees with timely and adequate feedback on their classroom learning. Related to this, most of the interviewees supported what one interviewee said that since the trainees were reluctant to engage in learning activities, he infrequently tried to engage them in learning activities and to provide constructive feedback on their learning. On the other hand, most of the interviewees maintained that as giving feedback on each and every academic activity was not a tradition in the universities, they did not give adequate and timely feedback to each of the trainees on each of the classroom learning aspect. Of course, after giving tests, exams and other assessment tasks, they sometimes used the assessment results for evaluation purpose but not for shaping and guiding the trainees' subsequent learning. This might have reduced the trainees' involvement in the knowledge construction process. Of course, for instance, in DMU, when the trainees utilized broken language and concepts in the classroom, one of the interviewees tolerated and encouraged the trainees to participate in the classroom discussion. However, since the class size was very large, the feedback was frequently given only to the trainees who raised their hands and answered to the instructor's questions. That meant that the instructor could not reach to every trainee to give feedback and support.

As to most of the interviewees, the lack of provision of feedback and support was related to the existence of large class size and the occurrence of shortage of instructional time that resulted from lately commencing of course offering. In addition to this, as one instructor who frequently lectured on a course consisting of 7-8 sections bulky course content within a month said, it was also related to the bulkiness of course content. Even though some interviewees used to give feedback on every assessment task to the trainees, they could not give feedback 
and support to each of a large number of the trainees assigned in a classroom within that short instructional time they had.

In this study, the trainees' perception score on the instructors' contribution to the trainees' experiential learning was compared across their demographic variables such as gender, prior teaching experience and undergraduate study CGPA. Accordingly, the independent samples ttest and the one way ANOVA results are presented in Table 3, table 4, and table 5 respectively.

Table 3. Results of t-test for Comparison of the Trainees' Rating Score on the Instructors' Contribution to the Trainees' Experiential Learning across Gender $(N=311)$

\begin{tabular}{|l|l|l|l|l|l|l|}
\hline Gender & $\mathrm{N}$ & Mean & SD & Df & T & Sig \\
\hline Male & 217 & 26.47 & 4.78 & 309 & -.456 & .649 \\
Female & 94 & 26.74 & 4.82 & & & \\
\hline
\end{tabular}

$P>0.05$

As the t-test result shows (table 3), there was no a statistically significant difference in the mean rating scores of male and female trainees on the contribution of the instructors to the trainees' experiential learning ( $t(309)=-.456, P>0.05)$. That is, the instructors' mean contribution to the experiential learning of both male and female trainees was below that of the expected one (30).

Table 4. Results of t-test for Comparison of the Trainees' Rating Score on the Instructors' Contribution to the Trainees' Experiential Learning across Teaching Experience $(\mathrm{N}=311)$

\begin{tabular}{|l|l|l|l|l|l|l|}
\hline Teaching Experience & $\mathrm{N}$ & Mean & SD & Df & $\mathrm{T}$ & Sig \\
\hline Experienced & 41 & 25.73 & 5.21 & 309 & -1.184 & .237 \\
Unexperienced & 270 & 26.68 & 4.72 & & & \\
\hline
\end{tabular}

$P>0.05$

As table 4 depicts, the t-test result did not show statistically significant difference in the mean rating scores of experienced and unexperienced trainees ( $t(309)=-1.184, P>0.05)$. That is, the instructors provided below the expected mean support to the experiential learning of both experienced and unexperienced trainees. This implies that the instructors did not provide differentiated support to the trainees' experiential learning based on their teaching experience.

Table 5. Results of One Way ANOVA for Comparison of the Instructors' Contribution to the Trainees' Experiential Learning across CGPA ( $N=311)$

\begin{tabular}{|l|l|l|l|l|l|}
\hline Source of Variation & Sum of Squares & Df & Mean Square & F & Sig. \\
\hline Between Groups & 36.072 & 2 & & & \\
Within Groups & 7072.693 & 308 & 18.036 & .785 & .457 \\
Total & 7108.765 & 310 & 22.963 & & \\
\hline
\end{tabular}

$\mathrm{P}>0.05$

As table 5 portrays, the one way ANOVA result confirmed that statistically significant difference was not found among the mean rating scores of the trainees on the instructors' contribution to the trainees' experiential learning across CGPA. That is, all the trainees who 
accumulated CGPA $\leq 3.00$ (mean=26.95), between 3.00 and 3.50 (mean=26.21) and $\geq 3.50$ (mean=26.43) obtained similarly below the expected mean support of the instructors (30) to their experiential learning $(F(2,308)=.785, \mathrm{P}>0.05)$. This implies that differentiated instructor support was not provided to the trainees who accumulated different CGPA in their undergraduate study.

\section{Discussion}

In this research, attempt was made to investigate the role of instructors in facilitating the trainees' experiential learning. In doing so, the analyses of the quantitative and qualitative data were made separately. But, the findings of the quantitative and qualitative data analyses were discussed concurrently below.

As the descriptive statistics presented in table 1 show, on average the instructors' contribution to the trainees' experiential learning was 26.56 (53.12\%). This indicates that the instructors' contribution to the trainees' experiential learning was less than that of their expected average contribution (60\%). In other words, the instructors' contribution to the trainees' involvement in the knowledge construction process was less than that of the expected contribution.

Likewise, in table 2, the one sample t-test statistics revealed that the rated mean value (26.56) of the trainees' observation on the instructors' contribution to the trainees' experiential learning was significantly less than that of their expected mean value (30.00). That is, the instructors' contribution to the trainees' experiential learning significantly fell below their anticipated contribution to the trainees' experiential learning. Similarly, the qualitative data analysis findings showed that the instructors' role had limitation in facilitating the trainees' experiential learning.

In experiential learning which is not usually mediated or taught (Moon, 2004), instructors are facilitators who support learners to actively construct their own meaning of the learning material from what they experience (Boud, at al., 1993). By facilitating the flexible reorganization of classroom place and space that contributes positively to student engagement, collaboration and learning, the instructors can support learners to construct their own knowledge in the learning material (Neill and Etheridge, 2008). However, in this programme, the instructors who frequently encouraged the trainees' seating arrangement to be rigidly organized in rows face to face to the blackboard facilitated the trainees' absorption of highly organized instructors' knowledge in a learning material from detailed PowerPoint presentations and long lecture note written on the blackboard. That is, the instructors who failed to flexibly reorganize the trainees' seating arrangement for group discussions and other active learning strategies facilitated the trainees' absorption of the instructors' knowledge than supported the trainees' own knowledge construction in a learning material. This in general contradicted to the contemporary pedagogical approaches to learning that emphasize learning orientation than teaching orientation (Jaskari, 2009).

Many individuals learn best and become proficient in skills when they participate in learning activities than passively listen to or observe what instructors do (Hermin and Toth, 2006). Thus, there is a need to utilize learning activities that support the constructivist model of learning in the instruction. That is, the learning activities to be provided to learners should be ones that allow learners to actively collect information, process that information and construct their own meaning in the learning material (Moon, 2004; Silberman, 1996). 
However, in this teacher education programme, the instructors frequently lectured on the course content than provided the trainees with learning activities that facilitate their knowledge construction. In other words, the learning activities were most of the time limited to listening to the instructors' lecture and taking notes. Thus, they were likely to facilitate a transmission model of learning that empowers an instructor to transmit his/her own knowledge in a course to learners (Anderson et al., 2001; Moon, 2004). That meant that learning by listening to what the instructors talked about the course contents helped the trainees to absorb information for the purpose of passing tests and exams than to construct their own knowledge in the learning material.

The instructors who lately commenced course delivery encountered shortage of instructional time. Consequently, they made lectures on bulky course content within the remaining short period of instructional time than involved the trainees in the instruction. In addition to this, the trainees' low interest to the teaching profession and entrance into conflict with the university administration body that could not provide them with services such as food, dormitory, and pocket money payment on time discouraged their involvement in the instruction. That is, these unfavorable conditions encouraged them to read the hand out and sit for exam than to involve in learning activities that facilitate experiential learning.

Effective constructive learning occurs in instructions involving small learning groups, collaborative work, and availability of opportunities for interaction, communication, and cooperation among the individual student and others in the learning environment (Salomon, 1993). In line with this, experiential learning involves cooperative learning that enables individuals to construct shared concepts and skills in the learning material (Ernest, 1996). This cooperative learning can be facilitated by supporting the learners' classroom interaction and discussion. As one element of the external learning environment of a learner (Beard, 2010), a teacher is a main agent that initiates and facilitates the learners' classroom interaction and discussion. However, in this teacher education, most of the instructors who frequently lectured to cover large course content within a short period of instructional time could not adequately initiate and facilitate the trainees' classroom interaction and discussion. That is, as the trainees most of the time individually absorbed what their instructors told about the course content, most of the instructional practices facilitated individual than cooperative learning. This does mean that although experiential learning requires learning to be social (Simons et al., 2000b), the trainees most of the time individually absorbed the transmitted instructors' knowledge in the courses. This matched with the finding of the quantitative data that disclosed that the instructors' contribution to the trainees' experiential learning practice was significantly lower. Of course, few instructors who infrequently initiated and facilitated the trainees' involvement in pair and small group discussions positively contributed to the trainees' experiential learning.

In this regard, first of all, the limited chance that the trainees got to interact and discuss among themselves in pair and small learning groups resulted from the instructors' delayed commencement of course delivery. That is, the delay resulted in shortage of instructional time that encouraged the instructors to make frequent lecture on bulky course content within the remaining short period of instructional time. Of course, the low interest of the trainees to the program and the classrooms crowded with armchairs and wide and long rectangular tables contributed to the trainees' individual absorption of the transmitted information. 
As Jonassen (1991) argued, experiential learning is an active process of interpreting and constructing individual knowledge representations. The social learning environments that encourage the exchange of information and offer opportunities for feedback and support are most likely to support experiential learning (Chism, 2006). Contrary to this, in this teacher education programme, the trainees received limited emotional support and academic feedback on learning tasks and assessment results from their instructors in the classroom. Particularly, due to lack of provision of the trainees with immediate feedback on the assessment results, the instructors could not focus learning, motivate learning, and shape/direct learning (Moon, 2004). This was likely to reduce the trainees' involvement in the knowledge construction process.

If learning from feedback is to be effective, programmes should be designed to include dedicated time allocated for reflection after feedback is given (Quinton and Smallbone, 2010). Nevertheless, in this programme, the instructors who lately commenced course delivery resulted in shortage of instructional time. Consequently, for they frequently used the remaining short period of instructional time to lecture bulky course content, they were not likely to provide the trainees with the required feedback and support. The result seemed to be reduction of the trainees' involvement in the knowledge construction process.

Of course, particularly, some of the subject matter teachers infrequently provided feedback to the individual or group learning tasks done and presented to the class. In addition, some instructors infrequently gave feedback on test and exam results and group assignment works. But, the feedback was most of the time limited to showing mistakenly or correctly done assessment tasks, mostly at the end of course delivery. Moreover, having taken tests and exams, the trainees did not most of the time receive immediate feedback on test and exam results. Rather, they frequently used to see only the final assessment letter grades at the end of the course delivery. Such kind of feedback given at the end of the course delivery was not that much relevant to the trainees' involvement in the instruction. Because, so that feedback offers individuals an additional experiential base for reflection, it should have been given during the course delivery (Quinton and Smallbone, 2010).

In addition to the instructors' delay in commencing course offering on time, the reluctance of the trainees to engage in learning experiences and lack of the universities' tradition to give feedback on each academic activity to the trainees contributed to the reduction of the provision of timely feedback and support. In addition, the existence of large class size and bulky course content hindered the provision of feedback and support to each of a large number of the trainees assigned in a classroom. In general, all these contributed to the reduction of the trainees' involvement in the knowledge construction process.

\section{Conclusions}

The current study sheds light on the status of the instructors' contribution to the trainees' experiential learning in the target universities. In this regard, the findings of the study enabled the researcher to conclude that the instructors had limitation in facilitating the trainees' experiential learning. That is, the instructional role that the instructors played to facilitate the trainees' experiential learning was significantly lower. To state specifically,

- The instructors who encouraged the trainees' seating arrangement to be rigidly organized in rows face to face to the blackboard facilitated the trainees' individual absorption of highly organized instructors' knowledge in a learning material. That 
meant that the trainees who were not urged by instructors to flexibly reorganize their seating arrangement in such a way that facilitates their involvement in the instruction passively absorbed the instructors' knowledge in the subject of the study than constructed their own knowledge.

- The instructors who frequently limited learning activities to listening to lectures and taking notes from lectures facilitated the transmission model of learning that empowers an instructor to transmit his/her own knowledge in a course to learners. That is, they frequently made the trainees passive absorbents of the transmitted information for the purpose of passing tests and exams than active constructors of their own knowledge in the learning material.

- The instructors who frequently facilitated individual absorption of the transmitted information than the trainees' cooperative learning in small learning groups appeared negatively affected the trainees' construction of shared concepts and skills in the learning material.

- The instructors who repeatedly provided the trainees with limited emotional support and academic feedback on learning tasks and assessment results contributed to the reduction of the trainees' involvement in the instruction. Consequently, the trainees used to absorb the transmitted course related information than constructed their own meaning in the learnt courses.

\section{Recommendations}

Based on the findings uncovered and the conclusions made, it was possible to recommend that:

- The officials should recruit the trainees with high interest to work in the teaching profession and reduce the classroom size so that instructors can reach each trainee and support their learning. They should also furnish classrooms with chairs and small square tables that have adequate space to do with different learning activities cooperatively.

- The officials and instructors should work cooperatively to commence course delivery on the set instructional time.

- Whatever challenge faces them, the instructors should encourage the trainees to flexibly reorganize their classroom seating arrangement in such a way that facilitates their engagement, interaction, communication, cooperative learning and application of what they learn.

- The instructors should frequently provide the trainees with learning activities that involve the trainees in the instruction than that make them passive absorbents of the transmitted information.

- The instructors should frequently create a cooperative learning environment that facilitates the trainees' construction of shared concepts and skills in the learning material.

- To facilitate experiential learning, the instructors should provide the trainees with a required emotional support and academic feedback on learning tasks and assessment results. 


\section{Reference}

Adula B. and Kassahun M. (2010). Enactment of student-centered approach in teaching mathematics And natural Sciences: The case of selected general secondary schools in Jimma zone, Ethiopia, Ethiop. J. Educ. \& Sc., 5(2), 29-50.

Ahmed, S. (2013). Teacher education in Ethiopia: Growth and development, African Journal of Teacher Education, 3(3), 1-20.

Ambrose, S., Bridges, M., DiPietro, M., Lovett, M., and Norman, M. (2010). How learning works: 7 research-based principles for smart teaching. San Francisco, CA: Jossey-Bass.

Anderson et al. (eds), (2001). Taxonomy for learning, teaching, and assessing, A revision of Bloom's taxonomy of educational objectives. New York: Longman.

Ausburn, L. J., \& Brown, D. (2006). Learning strategy patterns and instructional preferences of career and technical education students. Journal of Industrial Teacher Education, 43(4), 6-39.

Ayalew, S. (2009). Secondary School Teacher Deployment in Ethiopia: Challenges and Policy Options for Redressing the Imbalances. Addis Ababa University.

Bartle, E. (2015). Experiential learning: an overview. Institute for Teaching and Learning Innovation. The University of Queensland, Australia.

Beard, C. (2010). The experiential learning toolkit: blending practice with concepts. London: Kogan Page.

Behr, T. and Temmen, K. (2012). Teaching Experience - Improving Teacher Education with Experiential Learning, International Journal on New Trends in Education and Their Implications. Paderborn University, Germany, 3(3), 60-73.

Black, A. and Ammon, P. (1992). A developmental-constructivist approach to teacher education, Journal of Teacher Education, Kendall/Hunt, Dubuque, 43(5), 323-335.

Bonwell, C. C. (1996). Enhancing the lecture: Revitalizing a traditional format, New Directions for Teaching and Learning, (67), $31-44$.

Borko, H. (2004). Professional Development and Teacher Learning: Mapping the Terrain. Educational Researcher, 33(8), 3-15. http://dx.doi.org/10.3102/0013189X033008003.

Boud, D., Cohen, R. and Walker, D. (1993). Using experience for learning. Buckingham and Bristol SRHE and the Open University Press.

Bransford, J. D., Brown, A. L., and Cocking, R. R. (2000). How people learn: Brain, mind experience, and school. Washington DC: National Academy Press.

Borzak, L. (1981). Field study, A source book for experiential learning. Beverly Hills, CA : Sage.

Colton, D. and Covert, R. W. (2007). Designing and constructing instruments for social research and evaluation. John Wiley \& Sons, Inc. Jossey-Bass, San Francisco, CA 94103741-www.josseybass.com

Cooper, L., Orrell J., and Bowden, M. (2010). Work Integrated Learning: A guide to effective practice. New York, NY: Routledge.

Darling-Hammond, L. (2000). Teacher quality and student achievement: A review of state policy evidence. Education Policy Analysis Archives, 8, http://epaa.asu.edu/epaa/v8n1/.

Dewey, J. (1897). My pedagogic creed. The School Journal, 54, 77-80.

Dewey, J. (1938). Experience and education. New York, NY: Collier Macmillan Publishers.

Ernest, P. (1996). The one and the many. Steffe, L. \& J. Gale (Eds.) (1996). Constructivism: Theory, perspectives and practice. pp. 8-33. New York: Teachers College Press.

Fink, L. D. (2003). Creating Significant Learning Experience: An integrated approach to designing college courses. San Francisco: Jossey-Bass.

Fry, H., Ketteridge, S., and Marshall, S (Eds). (2009). A handbook for teaching and learning in higher education: Enhancing academic practice (3rd ed.). New York, USA: Routledge. 
Gamble, J., Davey, H. and Chan, P. (1999). Student experiences of reflection in learning in graduate professional education. Presented at HERDSA Annual International Conference, Melbourne.

Harris, D. and Sass, T. (2008). Teacher training, teacher quality and student achievement. Working paper 3 Available at http://files. eric.edgov/full text/ED509656.pdf.

Hermin, M. and Toth, M. (2006). Inspiring Active Learning: Complete handbook for teachers. Alexanderia, VA: Association for Supervision and Curriculum Development (ASCD).

Jaskari, M. M. (2009). Developing a Creative and Effective Physical Learning Space for Business Students - a Learner-centred Approach. Proceedings of the Academy of Marketing Annual Conference.

Jonassen, D. H. (1991). Objectivism versus constructivism: Do we need a new philosophical paradigm? Educational Technology Research and Development, 39(3), 5-14.

Kolb, D. (1984). Experiential Learning: Experience as the source of learning and development, New Jersey: Prentice-Hall.

Kolb, A. Y., and Kolb, D. A. (2005). Learning style and learning spaces: Enhancing experiential learning in higher education. Academy of Management Learning \& Education.

Kolb, A., and Kolb, D. (2009). The learning way: Meta-cognitive aspects of experiential learning. Simulation Gaming, 40(3), 297-327.

MacKinnon, A., and Scarff-Seatter, C. (1997). Constructivism: Contradictions and confusion in teacher education. In V. Richardson (Ed.), Constructivist Teacher Education: Building New Understandings. Washington, DC: Falmer Press.

Ministry of Education (2003). Teacher education system overhaul handbook. Addis Ababa: Ethiopia.

Ministry of Education. (2003). A National Curriculum Guideline for Pre-service Teacher Education Programme. Official working document, Addis Ababa: MOE.

Ministry of Education (2009). Postgraduate Diploma in Teaching (PGDT). Curriculum Framework for Secondary School Teacher Education Programme in Ethiopia. Addis Ababa.

Moon, J. A. (2004). A Handbook of Reflective and Experiential Learning: Theory and Practice. New York: Routledge Falmer Press.

Mpokosa, C. and Ndaruhutse, S. (2008). Managing Teachers: The centrality of teacher management to quality education. Lessons from developing countries. London: $\mathrm{CFBT}$ and vSO.

Mulugeta, T. (2009). Evaluation of implementation of the paradigm shift in EFL teacher education in Ethiopia. Addis Ababa University. Ethiopia.

Neill, S. and Etheridge, R. (2008). Flexible Learning Spaces: The Integration of Pedagogy, Physical Design, and Instructional Technology, Marketing Education Review, 18(1), 4753.

O' Loughlin, M. (1992). Engaging teachers in emancipatory knowledge construction. Journal of teacher education, 43(5), 336-346.

Quinton, S., and Smallbone, T. (2010). Feeding Forward: Using Feedback to Promote Student Reflection and Learning-A Teaching Model, Innovations in Education and Teaching International, 47(1), 125-135.

Rasmussen, C. (2015). Adults as learners: Effective teaching strategies. Workforce solutions conference. Regents of the University of Minnesota, Center for Community Vitality.

Reda, D. (2015). Competency-Based Secondary Teacher Education Programme in Ethiopia: Potential Opportunities and Obstacles. BJE, 15(1), 41-64.

Robert W. C, Mark D. T, and John C. E (2010). The Potential of Experiential learning Models and Practices in Career and Technical Education \& Career and Technical Teacher Education. Journal of Career and Technical Education, 25(2), 46-62. 
Salomon, G. (Ed.). (1993). Distributed cognitions: Psychological and educational considerations. Cambridge, UK: Cambridge University Press.

Silberman, M. (1996). Active learning: 101 strategies to teach any subject. Allyn \& Bacon.

Smith, M. K. (2001). David A. Kolb on experiential learning. Encyclopedia of informal education.

Tabot, B. A. and Mottanya, C. N. (2012). Effect of contextual characteristics of teaching practice schools on student teachers' performance in Kenya, Journal of Emerging Trends in Educational Research and policy studies, 3(3). 247- 256.

Tatto, M. T. (1998). The influence of teacher education on teacher's beliefs about the purpose of education, roles, and practice. Journal of teacher education, 49(1), 66-76.

Transitional Government of Ethiopia (TGE, 1994). Education and training policy. St. George printing press. Addis Ababa.

Wells, G. (1995). Language and the Inquiry-oriented Curriculum. Curriculum Inquiry.

Wortman, R. (1988). Pre-service, In-service, and the Late Blooming Leos. The Missouri Reader.

Zeichner, K., and Gore, J. (1990). Teacher socialization. In R. W. Houston (Ed.), Handbook of research on teacher education. New York: Macmillan (PP.329-348).

\section{Biographical notes:}

Kindie Birhan Fenta has completed his First Degree in pedagogical sciences in Bahir Dar University in Ethiopia. He earned his Master's Degree in Curriculum and Instruction from Addis Ababa University in Ethiopia and earned his PhD in Curriculum and Instruction from Bahir Dar University in Ethiopia. His main filed of interest and study is teaching methodology. 